\title{
Relationship Between Cluster Compactness and Bunch Rot in Vignoles Grapes
}

\author{
Bryan Hed, Department of Plant Pathology, Penn State University, Lake Erie Regional Grape Research and Exten- \\ sion Center, North East, PA 16428; and Henry K. Ngugi and James W. Travis, Department of Plant Pathology, \\ Penn State University, Fruit Research and Extension Center, Biglerville, PA 17307
}

\begin{abstract}
Hed, B., Ngugi, H. K., and Travis, J. W. 2009. Relationship between cluster compactness and bunch rot in Vignoles grapes. Plant Dis. 93:1195-1201.

The impact of cluster compactness and debris retention on harvest bunch rot of Vitis interspecific hybrid 'Vignoles' was investigated between 2001 and 2005 near Lake Erie, in Pennsylvania. Cluster compactness was characterized subjectively based on the OIV code 204 standard and objectively by determining the number of berries per centimeter of rachis. In 2001, 2002, and 2004, the median number of berries per centimeter for loose clusters was 6.3, 7.0, and 6.4 compared with 10.2, 12.7, and 12.4 for the compact clusters, respectively. Kolmogorov-Smirnoff and the Mann-Whitney U two-samples tests confirmed that the distribution of the berries per centimeter was significantly $\left(90 \leq \chi^{2} \leq 184.3 ; P<0.0001\right)$ different between the two subjective compactness categories. Cluster compactness was strongly correlated with bunch rot incidence $\left(\chi^{2}=\right.$ 73.1 and 62.2 for 2001 and 2002, respectively; $P<0.0001$ ), whereby disease incidence was higher in compact than in loose clusters. Logistic regression analysis indicated that every additional berry per centimeter unit of compactness almost doubled the likelihood of a cluster becoming infected with bunch rot (odds ratio $=1.828,95 \%$ confidence interval $[\mathrm{CI}]=1.392$ to 2.399 in 2001 and odds ratio $=1.705,95 \% \mathrm{CI}=1.394$ to 2.085 in 2002). In 2004, bunch rot severity in compact clusters was nearly four times that of loose clusters. Linear regression analysis revealed that berries per centimeter accounted for $>89 \%$ of the variation in bunch rot severity $\left(R^{2}=0.893, P<0.0001, n=30\right)$ and $>74 \%$ in cluster weight $\left(R^{2}=0.745, P<0.0001, n=30\right)$. Accumulations of dehiscent floral debris contributed to greater bunch rot severity, and the effect was more pronounced in compact clusters than in loose clusters. Removal of basal leaves at trace bloom reduced berries per centimeter by $13 \%$ in 2004 and $>25 \%$ in 2005, with corresponding reductions in bunch rot severity of $60 \%$ in 2004 and 62.5 to $82 \%$ in 2005 . These results indicate that berries per centimeter is a good indicator of cluster compactness in Vignoles, and that practices that reduce cluster tightness would be effective in an integrated program for control of bunch rot on this cultivar.
\end{abstract}

Harvest bunch rot, primarily caused by Botrytis cinerea, is an important disease of wine grapes in the eastern United States. Bunch rot typically begins to develop in clusters after veraison as fruit begin to ripen. The Vitis interspecific hybrid 'Vignoles', a cold-hardy, white French hybrid cultivar, is a popular wine grape in the eastern United States, especially in the Lake Erie and Finger Lakes region of New York where it is grown for sweet dessert wines. Unfortunately, the productivity of Vignoles vineyards in the eastern United States is threatened by bunch rot. Reliance on fungicides alone has not provided consistent bunch rot control on Vignoles, and more integrated approaches are needed for sustainable production of this cultivar in the eastern United States. Fungicide trials for bunch rot control conducted for several years at the Lake Erie Regional Grape

Corresponding author: H. K. Ngugi
E-mail: hkn3@psu.edu

Accepted for publication 14 July 2009.

doi:10.1094/PDIS-93-11-1195

(C) 2009 The American Phytopathological Society
Research and Extension Center resulted in inconsistent results. Control with Botrytis spp.-specific fungicides alone was often unsatisfactory and varied between seasons regardless of material used, number of applications, and timing (20-22).

Vignoles produces small, compact clusters that are highly susceptible to bunch rot. Vail and Marois (23) examined bunch rot susceptibility in several grape cultivars and determined that those most severely affected produced the most compact clusters. They also demonstrated that compact clusters dried at a slower rate than loose clusters, resulting in a more favorable microclimate for development of severe bunch rot (23). Berries damaged as a result of overcrowding in compact clusters also may be difficult to protect with fungicides because spray coverage may be reduced as clusters become more compact.

Cultural practices such as modification of cluster compactness and removal of floral debris, which is thought to be a principal source of primary inoculum to initiate bunch rot $(10,11,26)$, may be effective tools in the integrated control of bunch rot. Reducing cluster compactness in Rhine Riesling, a cultivar with compact clusters, was more effective at reducing bunch rot than fungicides (1), and cluster loosening has recently been documented to reduce rot incidence on Tempranillo and Grenache grape in Spain (19). However, the relationships among cluster compactness, floral debris, and harvest bunch rot, the key prerequisites to a successful integrated program, have never been defined for $\mathrm{Vi}$ gnoles grape. This study was initiated to determine the relative importance of cluster compactness and debris retention to bunch rot development on Vignoles grape in the Lake Erie region of Pennsylvania. The specific objectives were to characterize cluster compactness in Vignoles grape and determine the relationship between compactness and bunch rot incidence and severity. The information gathered would serve as a basis for future efforts to design treatments that would reduce compactness and improve bunch rot management in cultivars with compact clusters.

\section{MATERIALS AND METHODS}

A series of monitoring experiments was carried out from 2001 to 2004 to assess the effects of cluster compactness and retention of floral debris on development of bunch rot. These experiments were observational and relied on clusters selected from a typical vineyard to represent two categories of cluster compactness (compact and loose). A separate experiment was set up in 2004 and repeated in 2005 to determine whether results obtained from observational studies could be confirmed by experiments in which cluster compactness is modified by leaf removal at trace bloom.

Experimental vineyard and maintenance. All data were collected from a 0.4ha vineyard of Vitis interspecific hybrid Vignoles at the Lake Erie Regional Grape Research and Extension Center in northwestern Pennsylvania. Clusters for each study were selected from the north (shaded) side of the trellis, where bunch rot is generally most severe. All vines in this study were not sprayed for Botrytis bunch rot during the study, although a standard spray program was applied for control of other fungal diseases. The fungicides (formulation and rate per hectare) used in this maintenance program were as follows: for 2001, three applications of myclobutanil (Nova $40 \mathrm{~W}$ at $350 \mathrm{~g} / \mathrm{ha}$ ), two applications of tebuconazole (Elite 45 $\mathrm{DF}$ at $280 \mathrm{~g} / \mathrm{ha}$ ), and four applications of mancozeb (Penncozeb $75 \mathrm{DF}$ at $4.5 \mathrm{~kg} / \mathrm{ha}$ ); in 2002, three applications of tebuconazole 
(Elite $45 \mathrm{DF}$ at $280 \mathrm{~g} / \mathrm{ha}$ ), three applications of mancozeb (Penncozeb $75 \mathrm{DF}$ at $4.5 \mathrm{~kg} / \mathrm{ha}$ ), one application of paraffin oil (JMS stylet oil at 2\%); in 2004, four applications of tebuconazole (Elite $45 \mathrm{DF}$ at $280 \mathrm{~g} / \mathrm{ha}$ ), four applications of mancozeb (Penncozeb $75 \mathrm{DF}$ at $4.5 \mathrm{~kg} / \mathrm{ha}$ ), two applications of quinoxyfen (Quintec at 280 $\mathrm{g} / \mathrm{ha}$ ), and one application of monopotassium phosphate (Nutrol at $9 \mathrm{~kg} / \mathrm{ha}$ ). No insecticides were applied to vines in 2001 . In 2002, a single spray of fenpropathrin (Danitol at $730 \mathrm{ml} / \mathrm{ha}$ ) was made at fruit set when berries were $4 \mathrm{~mm}$ in diameter before cluster closure. During the winter of 2002-03, the vineyard sustained severe trunk damage and little crop was produced for monitoring in the 2003 season. In 2004, three insecticide applications were made: fenpropathrin (Danitol at $779 \mathrm{ml} / \mathrm{ha}$ ) was applied on 23 June at end of bloom and 20 July (pea-size berries, after cluster closure), followed by carbaryl (4.675 liters/ha) on 5 August, about 2 weeks before veraison. Vines were fertilized annually with $84 \mathrm{~kg}$ of actual nitrogen per hectare.

Characterization and association of cluster compactness with bunch rot. In 2001, clusters on 98 grapevines in two adjacent rows in the center of the vineyard were examined shortly after bloom for cluster compactness and accumulations of floral debris. On 27 July, 80 loose and 80 compact clusters were flagged to determine the relationship between cluster compactness and predisposition to bunch rot. Compactness was assessed visually and by touch based on the OIV code 204 standard (8). Clusters were designated "compact" if the majority of the berries were held firmly in place by cluster pressure (i.e., a score of 7 to 9 on the OIV scale). In loose clusters, berries throughout the cluster were capable of movement and of being slid past each other when the cluster was gently twisted; such clusters would score 1 to 3 on the OIV scale. Just before harvest on 2 October, clusters were collected, weighed, and examined for bunch rot incidence (number of clusters with bunch rot in each compactness category), severity on each cluster (determined as the percentage of berries with disease symptoms), and accumulation or retention of floral debris (number of dehiscent caliptrae and flowers). The number of berries per centimeter of the main rachis, a measure of compactness $(6,7,25)$, was also determined for each cluster.

In 2002, 20 loose and 20 compact clusters were flagged in each of five blocks (a total of 100 clusters in each compactness category) scattered throughout the Vignoles vineyard. Each block was composed of two adjacent rows of nine vines each. Clusters were selected on 15 July just before cluster closure. The retained floral debris were removed from half the tight and half the loose clusters in each plot to create four categories of clusters: (i) loose, floral debris removed; (ii) loose, floral debris retained; (iii) compact, floral debris removed; and (iv) compact, floral debris retained. Clusters were harvested on a block-by-block basis (one block per day) between 19 and 23 September, weighed to determine individual cluster weight, and assessed for bunch rot incidence, accumulation of floral debris, and number of berries per centimeter of the main rachis as in 2001. A sample of debris (two pieces per cluster) from loose clusters with debris was placed in a moist chamber consisting of a wet filter paper in a $10-\mathrm{cm}$ petri dish (five pieces per dish) to verify that debris was a source of Botrytis inoculum.

Relationship between cluster compactness and bunch rot severity. The relationship between cluster compactness and bunch rot severity was investigated in 2002 and 2004. In 2002, data on cluster weight and bunch rot severity were obtained in the experiment described above. In 2004, in total, 300 clusters consisting of 20 loose, 20 compact, and 20 randomly selected clusters in each of five blocks were flagged for the study. Clusters were selected on 8 or 9 July, just before closure and, as in 2002, each block of clusters was flagged on two adjacent rows of nine vines each. Floral debris were removed from half of the compact and loose clusters and not removed from the other half (left at natural levels averaging 25 and 31 pieces per cluster for loose and compact clusters, respectively). To the randomly selected clusters, floral debris was added to approximately double the natural level (average of 59 pieces per cluster). Clusters were harvested between 23 and 25 September on a blockby-block basis (one or two blocks per day), weighed individually, and assessed for bunch rot incidence (whether or not a cluster had disease symptoms), severity (berries with bunch rot symptoms as a percentage of the total number of berries per cluster), retention of floral debris, and number of berries per centimeter of the main rachis as in 2001.

Effects of modification of cluster compactness on bunch rot severity. A separate field experiment was carried out in 2004 and repeated in 2005 to investigate the effects of modifying cluster compactness on bunch rot development. Cluster compactness was modified by removal of the four most basal leaves on a fruitbearing shoot at trace bloom. Removal of basal leaves at trace bloom has been shown to reduce cluster compactness in Vignoles and other grape cultivars (G. S. Howell, personal communication; 13-15).

The experiments were carried out with mature vines trained to a single-curtain, bilateral cordon (no-tie) system. Experimental treatments consisted of: no Botrytis fungicide with no leaf removal, no Botrytis fungicide with leaf removal, Botrytis fungicide cyprodinil (Vangard 75WG at 700 $\mathrm{g} / \mathrm{ha}$ applied at preclose and veraison) with no leaf removal, and Botrytis fungicide with leaf removal. Treatments were applied to three-vine plots in a randomized complete block design with four replications. Fungicides for Botrytis bunch rot were confined to three-vine plots with the use of a Friend covered-boom plot sprayer (Friend Manufacturing Corp., Gasport, $\mathrm{NY}$ ) at $1,379 \mathrm{kPa}$ pressure and $935 \mathrm{li}$ ters/ha. Fungicides and insecticides not normally effective on Botrytis spp. were applied to the entire vineyard with a Kinkelder air-blast sprayer (Kinkelder, Zevenaar, Holland) to control all other diseases and insects. Bunch rot incidence and severity were determined, as described above, from 50 clusters in the center of each plot. Effects on cluster compactness were determined from a randomly chosen subset of the 50 clusters; 24 in 2004 and 18 in 2005.

Data collection for all experiments. Just before harvest, each cluster was removed and individually placed in a plastic Ziploc bag. In the laboratory, each cluster was weighed (2002 and 2004 experiments only) and dissected to record the number of rotten and healthy berries on the main rachis and shoulder (if present), number of pieces of floral debris retained, and the presence or absence of grape berry moth larvae, Paralobesia viteana (Endopiza viteana). Only berries $>5 \mathrm{~mm}$ in diameter were counted; those $<5 \mathrm{~mm}$ diameter were considered shot berries and were not counted. Rachis length was measured from the first lateral branch (not the shoulder, if present) to the bottom of the cluster. A compactness measurement was derived by dividing the total number of berries on the main rachis with the length in centimeters of the main rachis starting at the first lateral below the cluster shoulder or wing (if there was one) and measuring to the end of the rachis. Berries on the shoulder, if present, were disregarded in this compactness measurement because they rarely develop bunch rot.

Statistical analyses. To assess whether sufficient differences in cluster compactness existed between cluster designated as compact or loose, histograms of number of berries per centimeter for each of the categories were plotted in SigmaPlot software (SigmaPlot for Windows, version 10; Systat Software Inc. San Jose, CA). Because of the large number of clusters assessed in each category, 80 in 2001 and 100 in 2002 and 2004 , it was not necessary to convert the number of clusters into percentages when constructing the histograms. To test whether the resulting frequency distributions were similar for the two cluster compactness categories, the data were subjected to Kolmogorov-Smirnoff and the Mann-Whitney U two-sample tests (17). For both the 2001 and 2002 data sets, categorical data analysis by means of contingency tables (18) was used to assess for association between bunch rot incidence 
and cluster compactness or retention of floral debris. Because floral debris was assessed as a count of pieces of floral tissue per cluster, a binary variable was computed for this analysis such that clusters with $\leq 5$ pieces $=0$ while those with $>5$ pieces $=1$. The relationship between cluster compactness (berries per centimeter) and bunch rot intensity (incidence and severity) for the 2001 and 2002 data sets was further investigated using logistic regression analysis. Use of logistic regression was necessary because the nonparametric tests confirmed that the clusters were drawn from two distinct categories of compactness. Logistic regression was also used to investigate the relationship between cluster weight and berries per centimeter in the 2002 data. For this purpose, a binary variable was constructed by placing clusters into a "heavy" or "light" category depending on whether their weight exceeded $98 \mathrm{~g}$, the average weight of all the 200 clusters. This binary variable was then used as the response variable in the logistic regression model. To illustrate the relationship between compactness and cluster weight for 2002, clusters were grouped into four quartiles representing the distribution of berries per centimeter. The mean weight of clusters in each of the quartiles was computed and plotted against the mean of berries per centimeter. Treatment effects in the 2004 data were modeled using Proc Mixed procedures with blocks as a random factor, and a least squares means statement was used to compute orthogonal contrasts between treatments. This approach was also used to analyze data from the 2004 and 2005 experiment that investigated the effects of cluster compactness modification treatments on bunch rot severity. The relationships between cluster compactness and bunch rot severity and yield for the 2004 data were further investigated by regressing within-block mean values of bunch rot severity and cluster weight on berries per centimeter. All statistical analyses were carried out using SAS (release 9.1; SAS Institute Inc., Cary, NC).

\section{RESULTS}

Characterization of cluster compactness. Visual inspection of histograms depicting the number of clusters in each berries-per-centimeter category revealed that, for all years, clusters deemed to be compact were drawn from populations with more berries per centimeter than those designated as loose (Fig. 1). For all 3 years, both the Kolmogorov-Smirnoff and Mann-Whitney $U$ tests revealed that the underlying distributions of berries per centimeter for the two compactness categories were highly significantly different $\left(90 \leq \chi^{2} \leq 184.3 ; P<0.0001\right.$ for the K-S test with data sets from all 3 years) in both shape and location (i.e., median). For example, the median number of berries per centimeter for the loose clusters was 6.3 , 7.0, and 6.4 for the 2001, 2002, and 2004 studies, respectively, compared with 10.2, 12.7, and 12.4 for the compact clusters. Based on the Mann-Whitney $U$ tests, the median differences calculated from these values were within $95 \%$ confidence intervals (CIs) in all 3 years. This result provided the justification for including visually selected clusters in the studies on
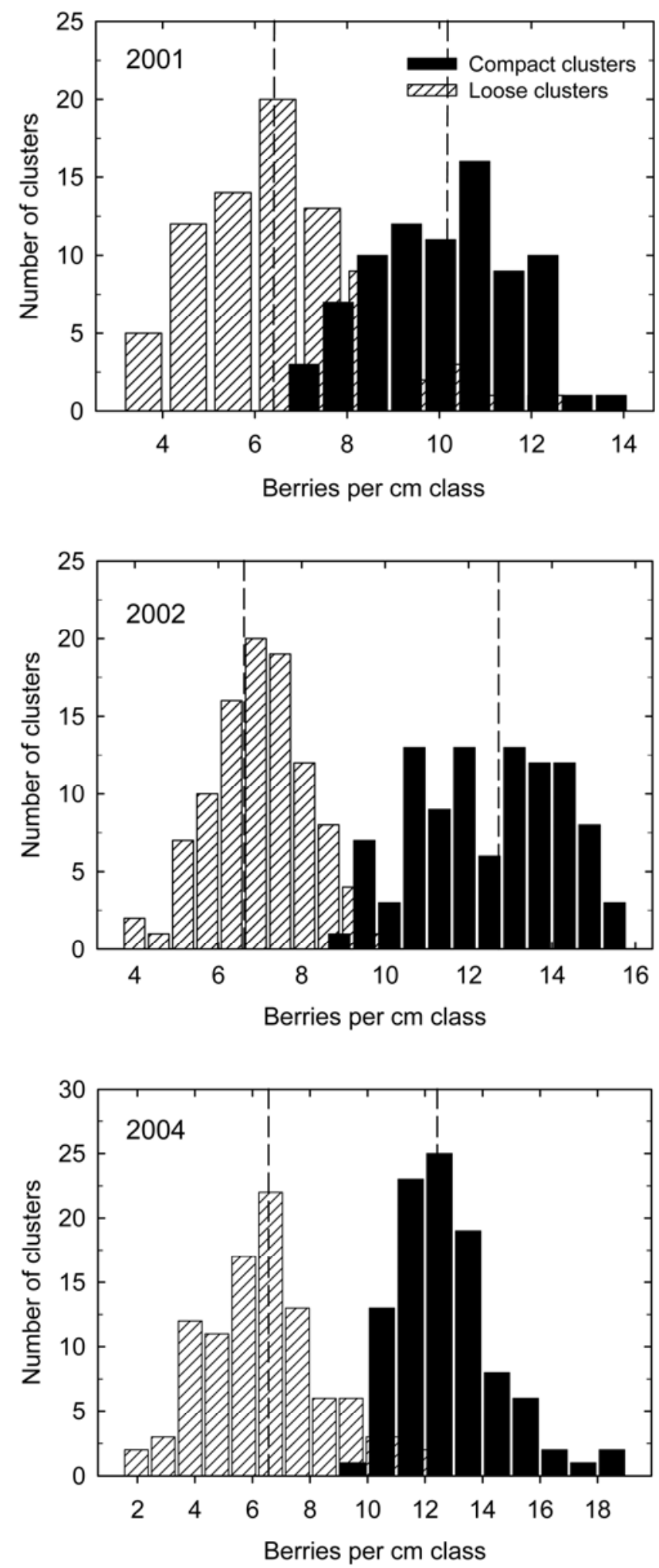

Fig. 1. Distribution of number of berries per centimeter for Vignoles grape clusters visually designated as either loose or compact during the 2001, 2002, and 2004 seasons near Lake Erie, PA. In all, 80 clusters in 2001 and 100 clusters in both 2002 and 2004 were visually placed in each compactness category based on the OIV code 204 rating standard. Dotted lines indicate significantly different median values for each compactness category $\left(90 \leq \chi^{2} \leq 184.3\right.$; $P<0.0001$ based the KolmogorovSmirnoff test). 
association of compactness with bunch rot incidence.

Association of cluster compactness and floral debris with bunch rot. Cluster compactness was strongly correlated with bunch rot incidence in both 2001 and 2002. In both years, the incidence of bunch rot was significantly $\left(\chi^{2}=73.1\right.$ and 62.2 for 2001 and 2002, respectively; $P<$
0.0001; Fig. 2) higher in compact than in loose clusters. For example, only $6.25 \%$ of loose clusters were infected with bunch rot in 2001 compared with $72.5 \%$ for the compact clusters (Fig. 2A). This pattern was observed in 2002 whereby, in spite of the higher disease pressure that resulted in a higher bunch rot incidence on loose clusters $(45 \%),>93 \%$ of the compact clusters
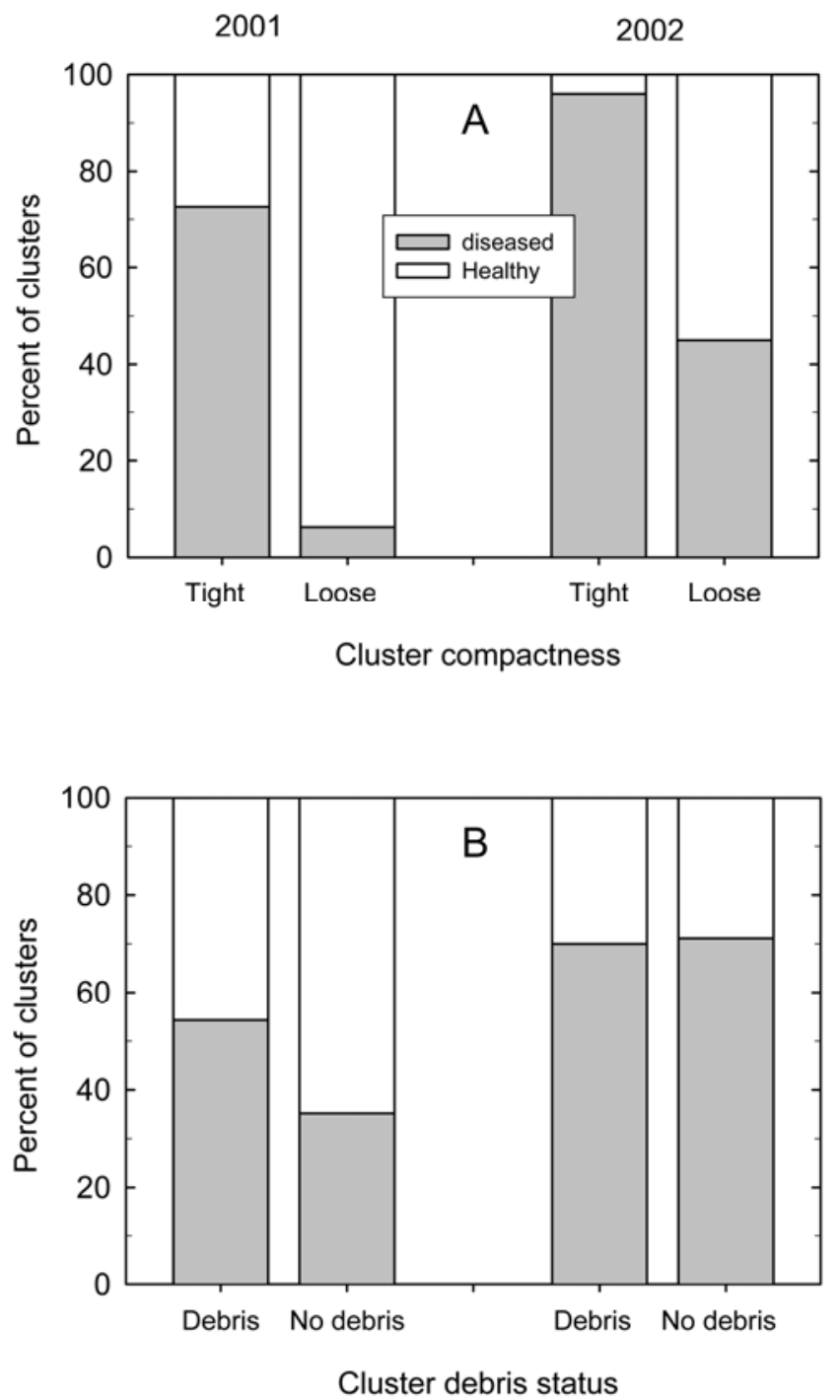

Fig. 2. Incidence of Botrytis bunch rot on Vignoles gape in clusters A, with tight or loose architecture and B, with or without floral debris near Lake Erie, PA in 2001 and 2002. Percent values in each debris category are based on 80 and 100 clusters for 2001 and 2002, respectively.

Table 1. Effect of cluster compactness and floral debris on severity of bunch rot of Vignoles grape near Lake Erie, PA in $2004^{y}$

\begin{tabular}{lcrrr}
\hline Treatment & $\begin{array}{c}\text { Berries per } \\
\text { centimeter }\end{array}$ & $\begin{array}{c}\text { No. of pieces } \\
\text { debris per cluster }\end{array}$ & \multicolumn{1}{c}{$\begin{array}{c}\text { Cluster weight } \\
(\mathbf{g})\end{array}$} & \multicolumn{1}{c}{$\begin{array}{c}\text { Bunch rot } \\
\text { severity }(\%)^{\mathbf{z}}\end{array}$} \\
\hline Debris added & $9.8 \pm 0.29 \mathrm{C}$ & $58.9 \pm 2.51 \mathrm{~A}$ & $108.6 \pm 3.57 \mathrm{C}$ & $17.9 \pm 1.96 \mathrm{~B}$ \\
Loose, debris & $6.5 \pm 0.31 \mathrm{D}$ & $25.3 \pm 3.11 \mathrm{~B}$ & $94.7 \pm 4.20 \mathrm{D}$ & $6.3 \pm 2.46 \mathrm{C}$ \\
Loose, low debris & $6.4 \pm 0.34 \mathrm{D}$ & $8.5 \pm 3.11 \mathrm{C}$ & $73.2 \pm 3.98 \mathrm{E}$ & $4.7 \pm 2.76 \mathrm{C}$ \\
Compact, debris & $13.0 \pm 0.39 \mathrm{~A}$ & $30.7 \pm 3.11 \mathrm{~B}$ & $143.2 \pm 7.03 \mathrm{~A}$ & $25.7 \pm 2.48 \mathrm{~A}$ \\
Compact, low debris & $12.3 \pm 0.35 \mathrm{~B}$ & $6.2 \pm 3.13 \mathrm{C}$ & $129.0 \pm 6.83 \mathrm{~B}$ & $15.5 \pm 2.54 \mathrm{~B}$ \\
\hline
\end{tabular}

y Values are means and standard errors of data from five blocks each with 10 clusters $(n=50)$ except for the Debris added treatment, for which 100 clusters were assessed. Means within a column followed by the same letter are not significantly different based on Fisher's protected least significant difference test $(\alpha=0.01)$.

${ }^{\mathrm{z}}$ Number of berries with bunch rot as a percentage of total number of berries per cluster.

were infected. Compact clusters also retained a significantly $(P=0.032)$ greater amount of floral debris in 2001 but not in 2002 (Fig. 2B).

In 2004, mean bunch rot severity in compact clusters (i.e., mean of compact cluster with or without debris) at $20.6 \%$ was nearly four times that of loose clusters (5.5\%; Table 1). Bunch rot severity in the 100 randomly selected clusters whose average compactness was approximately halfway between the compact and loose categories was $17.9 \%$ (Table 1). This level of disease was significantly $(P<0.01)$ lower than that observed in compact clusters with debris but not different from that on compact clusters without floral debris. Accumulations of dehiscent floral debris contributed to significantly $(P=0.008)$ greater bunch rot severity. In loose clusters, removal of debris reduced bunch rot by $25 \%$ whereas, in compact clusters, debris removal resulted in a $40 \%$ reduction in rot. Conversely, by doubling the natural accumulations of debris ("added"), bunch rot severity (17.9\%) was increased by nearly $12 \%$ compared with no removal (mean of loose and tight clusters with debris; $16 \%$ ). In all, $61 \%$ of the samples of debris collected from symptomless Vignoles clusters at harvest sporulated with Botrytis spp. when incubated in a moist chamber.

Relationship between cluster compactness and bunch rot severity. Logistic regression analysis revealed that, in both 2001 and 2002, cluster compactness, expressed as berries per centimeter, consistently affected bunch rot severity whereby compact clusters were at a significantly $(P$ $<0.0001$ in both years) higher risk of infection than loose clusters. Every additional berry-per-centimeter unit of compactness almost doubled the odds of a cluster becoming infected with bunch rot (odds ratio $=1.828,95 \% \mathrm{CI}=1.392$ to 2.399 in 2001 and odds ratio $=1.705,95 \%$ $\mathrm{CI}=1.394$ to 2.085 in 2002). A similar result was obtained from the 2004 data, in which case linear regression analysis revealed a strong linear relationship between bunch rot severity $(y)$ and berries per centimeter $(x)$ in which the cluster compactness explained $>89 \%$ of the variation in rot severity $\left(y=-24.59+4.15 x ; R^{2}=0.893 ; P\right.$ $<0.0001$; Fig. 3). Based on this equation, a cluster with $5.9 \pm 2.75$ (mean \pm standard error) berries per centimeter would not suffer any bunch rot.

There was also a strong positive relationship between cluster compactness and cluster weight in both 2002 and 2004. In 2002, logistic regression analysis showed that every additional berries-per-centimeter unit of compactness increased the odds of a cluster exceeding $98 \mathrm{~g}$, the mean weight of all the 200 clusters, by $32 \%$ (odds ratio $=1.32,95 \% \mathrm{CI}=1.087$ to $1.604, P<$ $0.01)$. This relationship was well depicted in a plot of mean values of cluster weight 
against berries per centimeter for the four quartiles describing the distribution of berries per centimeter (Fig. 4A). A similar result was obtained with the 2004 data, whereby berries per centimeter $(x)$ accounted for almost $75 \%$ of the variation in cluster weight $(g)$ in $2004(g=30.74+$ 8.22x, $r^{2}=0.745, P<0.0001$; Fig. 4B).

The effects of other explanatory variables were not consistent over the years. Thus, for example, whereas floral debris significantly affected bunch rot severity in 2001 and 2004, it had no effect on bunch rot severity in 2002 (data not shown). Conversely, insect damage was only sufficiently high enough to significantly $(P<$ 0.0001 ) affect bunch rot severity in 2002 .

Effects of modification of cluster compactness on bunch rot severity. Basal leaf removal at trace bloom significantly $(0.0001 \leq P \leq 0.0484)$ reduced the compactness and weight of the clusters in both 2004 and 2005. In 2004, a 13\% reduction in compactness led to a 51 and $60 \%$ reduction in bunch rot incidence and severity, respectively, but the differences were not significant. In 2005, cluster compactness and bunch rot incidence and severity were significantly $(0.0001 \leq P \leq 0.037)$ reduced by trace bloom leaf removal. A $26 \%$ reduction in compactness resulted in a 68 and $82 \%$ reduction in bunch rot incidence and severity, respectively, when Botrytis spp.specific fungicides were applied (Table 2). In unsprayed plots (no fungicide), a $25 \%$ reduction in compactness resulted in a 53 and $62.5 \%$ reduction in bunch rot incidence and severity, respectively. The efficacy of trace bloom leaf removal and $\mathrm{Bo}$ trytis spp.-specific fungicides were affected by year. In 2004, a wet year with severe disease, reductions in cluster compactness were only half that of 2005, a dry year with relatively low levels of bunch rot. However, the addition of two Botrytis spp.-specific fungicide applications significantly reduced bunch rot over an unsprayed check in 2004 (data not shown) but not in 2005, where leaf removal alone was significantly more effective than the fungicide program.

\section{DISCUSSION}

In this study, we found that bunch rot incidence and severity were strongly correlated with cluster compactness. Cluster compactness was initially determined by visual and tactile examination based on the subjective OIV scale (8). However, a more objective method was required to quantify compactness in order to study its relationship to bunch rot susceptibility. There are many methods of quantifying grape cluster compactness in the literature, including volumetric measurements, rachis length, number and weight of berries, force in newtons $(\mathrm{N})$ required to separate berries, as well as the number of berries per centimeter $(5,6,16,24,25)$. Among these, we chose to employ the number of berries per

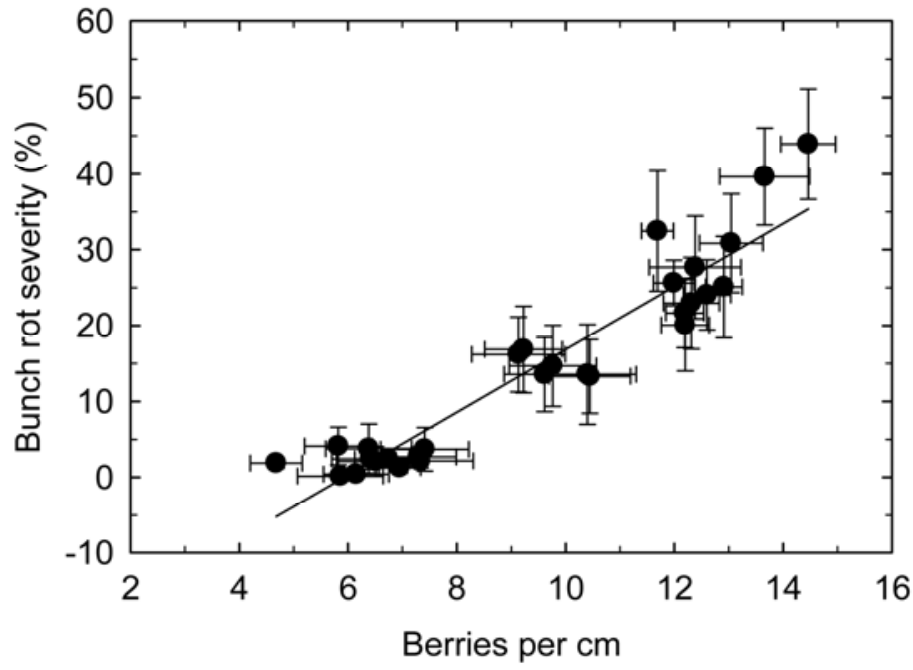

Fig. 3. Relationship between cluster compactness (berries per centimeter) and bunch rot severity of Vignoles grape near Lake Erie, PA in 2004. Values are means and standard errors of 10 clusters in each of thirty blocks. The line represents a linear regression relating bunch rot severity $(y)$ with berries per centimeter $(x)$ fitted to the values $\left(y=-24.59+4.15 x ; R^{2}=0.893 ; P<0.0001\right)$.
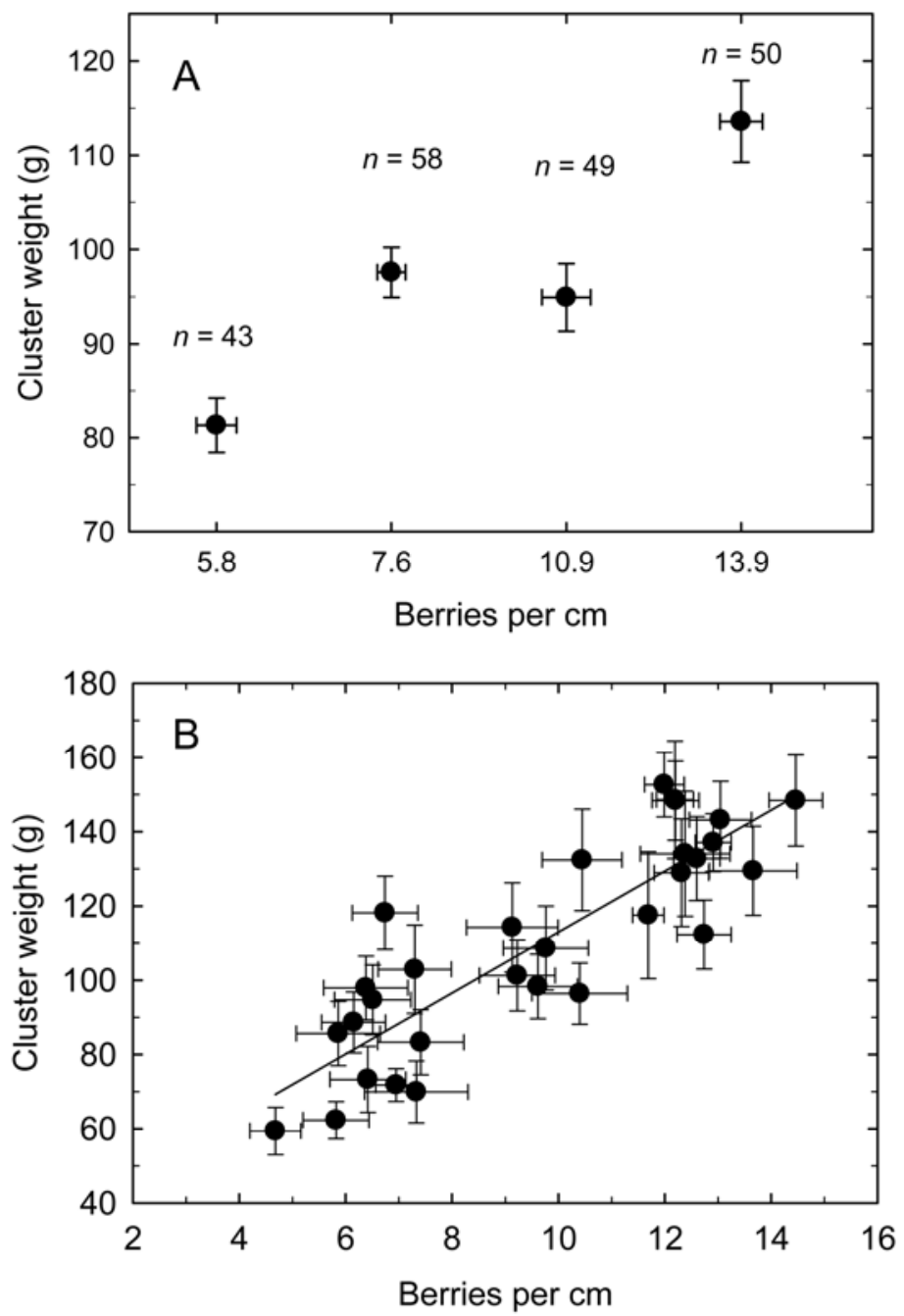

Fig. 4. Relationship between cluster compactness (berries per centimeter) and cluster weight of Vignoles grape near Lake Erie, PA in the A, 2002 and B, 2004 seasons. A, Values are means and standard errors of $n$ clusters in each of the four quartiles describing berries per centimeter. B, Values are means and standard errors of 10 clusters in each of thirty blocks. The line represents a linear regression relating cluster weight $(g)$ with berries per centimeter $(x)$ fitted to the values $\left(g=30.74+8.22 x ; r^{2}=0.745\right.$; $P<0.0001)$. 
Table 2. Effect of fungicide application and removal of basal leaves on cluster compactness, yield and Botrytis bunch rot on Vignoles grape near Lake Erie, $\mathrm{PA}$ in $2005^{\mathrm{w}}$

\begin{tabular}{|c|c|c|c|c|c|}
\hline Treatment $^{x}$ & $\begin{array}{l}\text { Berries per } \\
\text { centimeter }^{y}\end{array}$ & $\begin{array}{c}\text { Cluster weight } \\
\text { (g) }\end{array}$ & $\begin{array}{c}\text { Berry weight } \\
\text { (g) }\end{array}$ & $\begin{array}{c}\text { Bunch rot incidence } \\
(\%)\end{array}$ & Bunch rot severity ${ }^{\mathrm{z}}$ \\
\hline Fungicide only & $10.4 \pm 0.339 \mathrm{a}$ & $107.5 \pm 2.06 \mathrm{a}$ & $1.3 \pm 0.012 b$ & $26.0 \pm 0.82 \mathrm{ab}$ & $2.2 \pm 0.41 \mathrm{a}$ \\
\hline Fungicide + leaf removal & $7.7 \pm 0.366 b$ & $85.5 \pm 2.96 b$ & $1.4 \pm 0.011 \mathrm{a}$ & $8.3 \pm 0.85 \mathrm{c}$ & $0.4 \pm 0.09 \mathrm{~b}$ \\
\hline No fungicide, no leaf removal & $11.2 \pm 0.178 \mathrm{a}$ & $100.0 \pm 3.37 \mathrm{a}$ & $1.2 \pm 0.037 \mathrm{~b}$ & $37.0 \pm 9.32 \mathrm{a}$ & $3.2 \pm 1.09 \mathrm{a}$ \\
\hline Leaf removal only & $8.4 \pm 0.308 b$ & $81.0 \pm 0.41 \mathrm{~b}$ & $1.3 \pm 0.027 \mathrm{~b}$ & $17.3 \pm 1.11 \mathrm{bc}$ & $1.2 \pm 0.28 \mathrm{~b}$ \\
\hline
\end{tabular}

w Values are means and standard errors of four replicate blocks with 18 clusters per block. Means within a column followed by the same letter are not significantly different based on Fisher's protected least significant difference test $(\alpha=0.05)$.

x Plots were treated with cyprodinil (Vangard $75 \mathrm{WG} 700 \mathrm{~g} / \mathrm{ha}$ ) at preclosure and veraison.

y Measure of cluster compactness.

z Number of berries with bunch rot as a percentage of total number of berries per cluster.

centimeter for several reasons. Berries per centimeter is perhaps the metric most commonly used by viticulturists (23) and it is straightforward, relatively easy to assess, and related directly to our second objective of investigating the effects of cluster architecture modification on bunch rot incidence. Our results indicate that this metric is an excellent indicator of cluster compactness for Vignoles. In all 3 years, clusters visually judged to be compact had significantly more berries per centimeter compared with loose clusters (Fig. 1). Our results also show that berries per centimeter was consistently related to bunch rot incidence and severity. Moreover, treatments modifying this metric had the predicted effect of changing rot incidence and severity.

The finding that berries per centimeter is a good indicator of cluster compactness is in sharp contrast with the observations of Vail and Marois (23). These authors used a path analysis on data from four cultivars to examine several cluster architecture components often used as indicators of compactness and found berries per centimeter to have the least contribution to cluster compactness (23). However, their goal was to identify a method that could be applied to a wide range of compact and loose cultivars (23), or clones (24), and little effort was devoted to examining the withincultivar (or clone) variation in cluster compactness or its relationship to incidence and severity of bunch rot. Although not explicitly stated, apparently grape cultivar was not included as a variable in the path analysis. Including cultivar as a variable would have resulted in a significantly different outcome because the analyzed components are inherently correlated with cultivar. For example, the degree of lateral branching of individual clusters can vary dramatically between and within cultivars or clones $(3,9,23,27)$ and have a pronounced effect on compactness. As the ratio of lateral branch length to rachis length increases, the latter becomes less relevant as a component of compactness measurement. Therefore, berries per centimeter of rachis would not be expected to accurately assess compactness in cultivars with relatively extensive lateral development such as Vitis interspecific hybrid 'Chambourcin' or Vitis vinifera 'Cabernet Sauvignon'.
Berries per centimeter has been widely used by researchers to adequately define cluster compactness (6,7,25). Similarly, Christodoulou (2) measured berries per centimeter of rachis on the second and third primary laterals. We believe this metric was adequate for this study because clusters of Vignoles grape typically exhibit a relatively low degree of lateral development from the main rachis. Histograms obtained in this study also indicate that berries per centimeter is a normally distributed metric, making it ideal for standard statistical analyses that assume normal distribution (e.g., the linear regression analysis used in this study). In any case, cluster weight, the component that Vail and Marois (23) found to be the best indicator of compactness, was strongly correlated with berries per centimeter in this study, with berries per centimeter accounting for $>74 \%$ of the variation in cluster weight (Fig. 4).

The development of bunch rot in ripening grape clusters is a complex process, and cluster compactness can affect the severity of bunch rots in many ways. Percival et al. (12) showed that berry cuticle, an important barrier to infection, was reduced at points of berry contact and that the degree of contact (i.e., compactness) within a cluster can affect susceptibility to bunch rots. Experiments by Zitter and Wilcox (27) comparing a compact and relatively loose clone of Pinot noir demonstrated how the spread of bunch rot from a single point source within a ripening cluster occurs through berry-to-berry contact that is intensified within overcrowded clusters. Cluster compactness can affect the duration that clusters remain wet after rainfall events. In Vignoles, compactness is most pronounced at the bottom third of the cluster, and clusters can retain a lot of water during periods of precipitation. For example, in 2001, four short precipitation periods ( 2 to $3 \mathrm{~h}$ each) during 2 days in late August (veraison) resulted in only $6 \mathrm{~h}$ of wetness as registered by leaf wetness sensors. However, from the onset of rain, relative humidity remained above $80 \%$ for the next $48 \mathrm{~h}$ and compact clusters remained wet for at least 2 days.

The relationship between floral debris retention and cluster rot has received relatively little attention in eastern U.S. viti- culture. Wolf et al. (26) examined the removal of cluster debris as part of a management program for control of bunch rot on Chardonnay in Virginia. Their results showed that debris removal does not always result in significant reductions in bunch rot (26). Our results concur with their findings; retained floral debris can lead to greater bunch rot but the effect is not always consistent and may be dependent on other factors such as compactness, prevailing weather conditions, or even insect damage. For example, rainfall amounts during the ripening period may affect the role of retained debris on rot. In 2001 and 2004, for example, the ripening period was relatively wet; in 2001, it rained 18 of 41 days (44\%) for a total of $206 \mathrm{~mm}$ of rain and, in 2004, it rained 13 of 45 days (29\%) for a total of $381 \mathrm{~mm}$ of rain. Clusters with debris averaged more severe bunch rot than clusters with little or no debris (Fig. 2B; Table 1). In 2002, the weather during the ripening period was less conducive to disease development, with rain on only 11 of 42 days (26\%) totaling $140 \mathrm{~mm}$. The removal of retained debris had less of an effect on bunch rot development than in 2001 and 2004, despite much higher levels of retained debris in 2002. Instead, the higher levels of bunch rot that occurred among all groups of clusters in 2002 could be attributed to higher levels of grape berry moth infestation during ripening (6 and 3.3\% infestation in 2001 and 2004, respectively, versus $39 \%$ in 2002). After hatching, grape berry moth larvae bore into the fruit, leaving wounds that are easily colonized by Botrytis spp. and other rot organisms. Control of this insect pest, particularly during the ripening period, is critical to bunch rot management (4). On the other hand, it is notable that the effects of cluster compactness remained consistent and independent predisposing factors in all three seasons.

The degree of cluster compactness can affect the role of retained floral debris in several ways. First, compactness may affect the amount of floral debris retained to the time of berry ripening. Second, in compact clusters, greater contact is maintained between berries and debris, enabling retained debris to take on a greater role in rot development (11). Retained floral de- 
Table 3. Effect of removal of basal leaves on cluster compactness, yield, and Botrytis bunch rot on Vignoles grape near Lake Erie, PA in $2004^{\mathrm{w}}$

\begin{tabular}{|c|c|c|c|c|}
\hline Treatment $^{x}$ & $\begin{array}{l}\text { Berries per } \\
\text { centimeter }^{y}\end{array}$ & $\begin{array}{c}\text { Cluster weight } \\
\text { (g) }\end{array}$ & $\begin{array}{c}\text { Bunch rot } \\
\text { incidence }(\%)\end{array}$ & $\begin{array}{c}\text { Bunch rot } \\
\text { severity }(\%)^{\mathrm{z}}\end{array}$ \\
\hline Fungicide + leaf removal & $10.1 \pm 0.53 \mathrm{~b}$ & $85.5 \pm 3.24 b$ & $19.0 \pm 4.51 \mathrm{a}$ & $1.9 \pm 0.51 \mathrm{a}$ \\
\hline Fungicide only & $11.6 \pm 0.25 \mathrm{a}$ & $103.0 \pm 5.36 \mathrm{a}$ & $39.0 \pm 6.14 \mathrm{a}$ & $4.8 \pm 1.14 \mathrm{a}$ \\
\hline
\end{tabular}

${ }^{w}$ Values are means and standard errors of four replicate blocks with 24 clusters per block. Means within a column followed by the same letter are not significantly different based on Fisher's protected least significant difference test $(\alpha=0.05)$.

x Plots were treated with cyprodinil (Vangard $75 \mathrm{WG}, 700 \mathrm{~g} / \mathrm{ha}$ ) at preclosure and veraison.

${ }^{y}$ Measure of cluster compactness.

${ }^{\mathrm{z}}$ Number of berries with bunch rot as a percentage of total number of berries per cluster.

bris has been shown to harbor Botrytis spp. and, therefore, is a potential source of inoculum within clusters $(10,11,26)$. In this study, about $61 \%$ of the sampled pieces of symptomless debris harbored Botrytis spp.

Clusters compactness can also have direct effects on the efficacy of pesticide sprays applied to control insects and diseases. In the experimental vineyard, Vignoles bunches generally begin to close 2 weeks after bloom. By 4 weeks after bloom, many clusters are so compact that berries are distorted and some are forced from their pedicels. Subsequent fungicide and insecticide sprays may not penetrate to the inside surfaces of clusters during ripening, when fruit are most susceptible to bunch rot and control of insect damage is critical. Preliminary results in our program indicate that spray penetration decreases linearly as compactness increases (data not shown). Therefore, reduction of cluster compactness can improve spray penetration and the efficacy of chemical control programs. Indeed, improved spray penetration along with other factors may explain the lower levels of bunch rot documented in sprayed plots in our cluster-loosening experiments in 2005 (Table 2).

Little has been done to integrate cluster loosening in rot control programs for the wetter eastern climates of the United States, despite the heavy losses to rot sometimes incurred in wet harvest seasons. Instead, bunch rot control programs for compact cultivars depend heavily on $\mathrm{Bo}$ trytis spp.-specific fungicides that are timed mostly based on cluster phenology (bloom, preclosure, veraison, and preharvest). Our trials with leaf removal at trace bloom in 2004 and 2005 reduced cluster compactness and provided consistent rot reductions of 60 to $83 \%$ over no leaf removal. These results not only confirmed the relationship between compactness and bunch rot incidence and severity but also suggest that important gains in bunch rot control can be made if practical means of loosening clusters can be devised. Specifically, these data indicate that Vignoles clusters averaging $<9$ berries per centimeter would be expected to have little or no bunch rot (Fig. 3).

Cluster compactness and, hence, rot susceptibility in Vignoles is closely associated with berry number and cluster weight.
Treatments aimed at reducing compactness in Vignoles could reduce cluster weight with a potential yield reduction. Indeed, leaf removal treatments in both 2004 and 2005 resulted in significantly lighter clusters in this study (Tables 2 and 3). However, it is also feasible to reduce cluster weight without necessarily reducing the overall yield if more clusters are allowed to set. Moreover, early leaf removal has recently been shown to reduce cluster compactness without negative effects on yield and quality in Sangiovese and Trebbiano (13-15) and to also reduce bunch rot without adverse effects on Tempranillo and Grenache grape (19). Because cluster compactness is so strongly and consistently related to bunch rot severity in Vignoles, cluster loosening must be part of an integrated disease control program in the eastern United States. Cluster architecture modification studies with Vignoles are the subject of an ongoing study to be reported elsewhere.

\section{ACKNOWLEDGMENTS}

We thank J. Griggs, S. Abate, K. Timer, and A. Collins-Hed for field and laboratory support.

\section{LITERATURE CITED}

1. Barbetti, M. J. 1980. Reductions in bunch rot in Rhine Riesling grapes from bunch thinning. Aust. Plant Pathol 9:8-10.

2. Christodoulou, A. J., Weaver, R. J., and Pool, R. M. 1968. Relation of gibberellin treatment to fruit set, berry development, and cluster compactness in Vitis vinifera grapes. J. Am. Soc. Hortic. Sci. 92:301-310.

3. Dunn, G. M., and Martin, S. R. 2007. A functional association in Vitis vinifera L. cv. Cabernet Sauvignon between the extent of primary branching and the number of flowers formed per inflorencence. Aust. J. Grape Wine Res. 13:95-100.

4. Fermaud, M., and leMenn, R. 1989. Association of Botrytis cinerea with grape berry moth larvae. Phytopathology 79:651-656.

5. Ferree D. C., Ellis, M. A., McArtney, S. J., Brown, M. V., and Scurlock, D. M. 2003. Comparison of fungicide, leaf removal and gibberellic acid on development of grape cluster and Botrytis bunch rot of 'Vignoles' and 'Pinot Gris'. Small Fruits Rev. 2:3-19.

6. Guoguang, L., Chen X., and Wang Y., 1983. A preliminary study on methods and sample size in grapevine berry set evaluation. Acta Agric. Univ. Pekinensis 9 2:37-44.

7. Howell, G. S., Schutte, C., and Treloar, J. 2005. Controlled cultural reduction in fruit set and subsequent harvest season Botrytis cluster rot complex. N. Y. State Agric. Exp. Stn. Rep. Grant Year 2005.

8. IPGRI, UPOV, OIV. 1997. Descriptors for Grapevine (Vitis spp.). International Union for the Protection of New Varieties of Plants, Geneva; Office International de la Vigne et du Vin, Paris; International Plant Genetic Resources Institute, Rome

9. May, P. 2000. From bud to berry, with special reference to inflorescence and bunch morphology in Vitis vinifera L. Aust. J. Grape Wine Res. 6:82-98.

10. Nair, N. G., Emmett, R. W., and Parker, F. E 1988. Some factors predisposing grape berries to infection by Botrytis cinerea. N. Z. J. Exp. Agric. 16:257-263.

11. Northover, J. 1987. Infection sites and fungicidal prevention of Botrytis cinerea bunch rot of grapes in Ontario. Can. J. Plant Pathol. 9:129-136.

12. Percival, D. C., Sullivan, J. A., and Fisher, K. H. 1993. Effect of cluster exposure, berry contact and cultivar on cuticular membrane formation and occurrence of bunch rot (Botrytis cinerea PERS.:FR.) with 3 Vitis vinifera L. cultivars. Vitis 32:87-97.

13. Poni, S., Bernizzoni, F., Briola, G., and Cenni, A. 2005. Effects of early leaf removal on cluster morphology, shoot efficiency and grape quality in two Vitis vinifera cultivars. Acta Hortic. 689:217-225.

14. Poni, S., Bernizzoni, F., and Civardi, S. 2008. The effect of early leaf removal on wholecanopy gas exchange and vine performance of Vitis vinifera L. 'Sangiovese'. Vitis 47:1-6.

15. Poni, S., Casalini, L., Bernizzoni, F., Civardi, S., and Intrieri, C. 2006. Effects of early defoliation on shoot photosynthesis, yield components, and grape composition. Am. J. Enol. Vitic. 57:397-407.

16. Sepahi, A. 1980. Estimating cluster compactness in Yaghouti grapes. Vitis 19:81-90.

17. Sprent, P., and Smeeton, N. C. 2001. Applied Nonparametric Statistical Methods, 3rd ed. Chapman \& Hall, CRC Texts in Statistical Sciences, Boca Raton, FL.

18. Stokes, M. E., Davis, C. S., and Koch, G. G., 2000. Categorical Data Analysis Using the SAS System, Second ed. SAS Institute, Cary, NC.

19. Tardaguila, J., Petrie, P. R., Poni, S., Diago, M. P., and de Toda, F. M. 2008. Effects of mechanical thinning on yield and fruit composition of Tempranillo and Grenache grapes trained to a vertical shoot-positioned canopy. Am. J. Enol. Vitic. 59:412-417.

20. Travis, J. W., and Hed, B. 2000. Evaluation of fungicides for control of Botrytis bunch rot of grapes, 1999. Fungic. Nematicide Tests. Rep. No. 55:108. DOI:10.1094/FN55.

21. Travis, J. W., and Hed, B. 2001. Evaluation of fungicides for control of Botrytis bunch rot on grapes, 2000. Fungic. Nematicide Tests. Rep. No. 56:SMF31. DOI:10.1094/FN56.

22. Travis, J. W., and Hed, B. 2002. Evaluation of fungicides for control of Botrytis bunch rot of grape, 2001. Fungic. Nematicide Tests. Rep. No. 57:SMF16. DOI:10.1094/FN57.

23. Vail, M. E., and Marois, J. J. 1991. Grape cluster architecture and the susceptibility of berries to Botrytis cinerea. Phytopathology 81:188-191.

24. Vail, M. E., Wolpert, J. A. Gubler, W. D., and Rademacher, M. R. 1998. Effect of cluster tightness on Botrytis bunch rot in six Chardonnay clones. Plant Dis. 82:107-109.

25. Weaver, R. J., and Pool, R. M. 1971. Thinning 'Tokay' and 'Zinfandel' grapes by bloom sprays of gibberellin. J. Am. Soc. Hortic. Sci. 96:820-822.

26. Wolf, T. K., Baudoin, A. B. A. M., and Maritinez-Ochoa, N. 1997. Effect of floral debris removal from fruit clusters on Botrytis bunch rot of Chardonnay grapes. Vitis 36:27-33.

27. Zitter, S. M., and Wilcox, W. F. 2004. Ontogenic, physical, and cultural factors affecting the initiation and spread of botrytis bunch rot of grapes. In: XIII Botrytis Symposium, Antalya, Turkey. 